\title{
The social discount rate in the evaluation of investment projects: an application for Ecuador ${ }^{1}$
}

\author{
José Gabriel Castillo and Donald Zhangallimbay
}

\begin{abstract}
The standard social discount rate of $12 \%$ applied by planning institutions and multilateral agencies when evaluating public projects is a constant administrative parameter that is unsupported and unresponsive to changes in social preferences over time. This paper presents an alternative way of determining the social discount rate based on the gamma estimation model (Weitzman, 2001) in a developing-country context, which has three advantages: (i) it incorporates decreasing discounting, (ii) it is cost-efficient in that it sums up the various expert opinions and (iii) it adjusts for changes in short- and long-term preferences. Our estimates are lower than the standard nominal rate for different time periods, ranging from $2 \%$ for evaluation horizons longer than 51 years to $11 \%$ for the short term ( $0-5$ years).
\end{abstract}

\section{Keywords}

Investments, development projects, project preparation, project evaluation, equality, welfare economics, mathematical models, developing countries, Ecuador

JEL classification

O22, D04, C93

\section{Authors}

José Gabriel Castillo is the Director of the Centre for Economic Research (CIEC) and the Laboratory for Experimental and Behavioural Economics (LEE) at the Faculty of Social Sciences and Humanities (FCSH) of the Escuela Superior Politécnica del Litoral (ESPOL), Ecuador. Email: jcastil@espol.edu.ec.

Donald Zhangallimbay is a Coordinator and Researcher with the Laboratory for Experimental and Behavioural Economics (LEE) at the Faculty of Social Sciences and Humanities (FCSH) of the Escuela Superior Politécnica del Litoral (ESPOL), Ecuador. Email: djzhanga@espol.edu.ec.

\footnotetext{
1 This study has been financed by project research funds from the Centre for Economic Research (CIEC) and the Faculty of Social Sciences and Humanities (FCSH) of the Escuela Superior Politécnica del Litoral (ESPOL), Ecuador. It is a spin-off from the project "The social discount rate in Ecuador: an approach from experimental economics" (CIEC-19-2016).
} 


\section{Introduction}

Cost-benefit assessment is the main tool used to determine the economic viability of public investment projects. The social discount rate (SDR) is a key parameter in this analysis, most particularly because it represents the opportunity cost of resource use over time and serves to compare projected revenues and costs (net cash flows) over different periods. Thus, setting the SDR too high may mean that socially desirable projects are rejected; conversely, setting it too low may result in resources being wasted on economically inefficient projects (Zhuang and others, 2007). The choice of an appropriate discount rate is not a trivial exercise; on the contrary, it is a subject of intense debate in the economic and financial literature, particularly with regard to the development of efficient methodologies and strategies that can ensure optimal use of resources and sustainable social development (see Correa, 2008a, for a summary).

There is as yet no consensus on how to measure and establish an appropriate SDR (Campos, Serebrisky and Suárez-Alemán, 2015). However, growing social demands for administrative transparency and the intense debate on project externalities reflected in pollution and environmental impacts have led a number of countries to review the economic evaluation parameters used. The economies of Latin America and the Caribbean (e.g. Chile, Colombia and Costa Rica) are no exception. The region's remarkable progress with economic development and access to external financing points to a need to re-evaluate the SDR as a tool for analysing the efficiency and intergenerational equity of public investment (Campos, Serebrisky and Suárez-Alemán, 2015).

Three approaches are commonly applied to determine the SDR: (i) the social rate of time preference approach, (ii) the social opportunity cost of capital approach and (iii) the combined, weighted average or Harberger approach (Harberger, 1972). However, traditional techniques framed within a constant discount rate model are inefficient when it comes to evaluating projects with a large externality component that is not absorbed by the market, or projects with intergenerational effects (or very long-term effects), such as transport infrastructure, hospitals, roads and waste disposal projects. The search for parameters compatible with social preferences prompts a reconsideration of the effects of public investment, especially when the effect extends socially and economically to future generations who have no say in the investment decision (Correa, 2008b). The rates currently applied in a number of developing countries, e.g. Ecuador, omit several technical evaluation criteria and suggest a relatively high discount level that characterizes a preference for resource use in the short term and quickly discounts the economic benefits to be obtained in the distant future (Frederick, Loewenstein and O'Donoghue, 2002).

While a constant SDR facilitates the modelling and interpretation of economic flows, a vast empirical and experimental literature from both psychology and economics (see, for example, Thaler, 1981; Harrison and others, 2005; Benhabib, Bisin and Schotter, 2010; Castillo and Zhangallimbay, 2018) has revealed numerous anomalies in preferences over time that argue for a pattern of decreasing discount rates; i.e. the longer the waiting period for cash flows is, the more patient individuals tend to be, which translates into lower discount rates. This behavioural anomaly has already been taken into account in investment project evaluation approaches. In the United Kingdom, for example, the standard method for discounting flows in the long term (more than 30 years) uses declining rates that range from 3.5\% down to $1.0 \%$ (Lowe, 2008).

Delacámara (2008), meanwhile, recommends the use of an SDR that incorporates social preferences over time. In Ecuador, as in other Latin American countries, a fixed discount rate, usually of $12 \%$, is used. This rate does not derive from any estimation of individual or social preferences over time, but is an administrative rate suggested both by international agencies such as the Inter-American Development Bank (IDB) and the World Bank and by national planning institutions. A number of countries have undertaken a review of their SDR, with interesting outcomes; the resulting estimates are generally lower than the discount level actually applied. In Ecuador alone, the National Secretariat for Planning 
and Development (SENPLADES) uses the SDR to evaluate approximately 140 projects per year, and in none of these cases is any distinction made between short- and long-term implementation periods.

This study conducts a review of SDR estimation by distinguishing four evaluation periods, from the short to the long term: the immediate future (1-5 years), the medium future (6-20 years), the distant future (21-50 years) and the far distant future (51-100 years). Our estimates for a developing country, Ecuador, employ the gamma discounting mechanism, proposed by Weitzman (2001), to integrate the views of a diverse group of decision-makers, adapting a questionnaire so that it can be used to adjust the interval estimation and so refine the results (Edwards, 2016). Additionally, we present an adjustment in which we consider the present value bias generated by time preferences in a short-term context. The results show that the rates determined in this context differ from those estimated using the general long-term survey mechanism. Averaging the results obtained by both procedures, we observe a significant adjustment of the recommended rate for the immediate future (1-5 years), which represents an economically important argument against using the standard rate. Thus, the results suggest the use of a rate of $11 \%$ for the immediate future, $4 \%$ for the medium future, $3 \%$ for the distant future and $2 \%$ for the far distant future (for periods longer than 100 years, $1 \%$ is recommended). Lastly, we analyse factors related to respondents' SDR preferences and find that both age and levels of risk aversion are important conditions in shaping time preferences.

The rest of the article is organized into four sections. Section II presents a review of methodologies and results obtained by re-estimating SDRs in various countries. Section III details the methodology, the data and the adjustment applied to correct for the exposure biases in traditional questionnaires. Section IV presents the results of the study and a discussion of their implications. Lastly, section $\mathrm{V}$ presents the conclusions of the study.

\section{Methodological alternatives and international experience}

In the absence of consensus on the definition of the SDR and the mechanisms for estimating it, various ways of approximating this parameter can be found. Estimates made in a number of countries around the world (see table 1) show that the assumption of a constant rate derived from exponential discounting remains the most widely applied method (Campos, Serebrisky and Suárez-Alemán, 2015).

Table 1

Estimates of the social discount rate around the world

\begin{tabular}{|c|c|c|}
\hline Institution or country & Rate & Conceptual or theoretical basis \\
\hline \multicolumn{3}{|c|}{ Multilateral agencies } \\
\hline World Bank & $10 \%-12 \%$ & Conventional administrative rate \\
\hline Inter-American Development Bank & $10 \%-12 \%$ & $\begin{array}{l}\text { Conventional administrative rate/ } \\
\text { opportunity cost of capital }\end{array}$ \\
\hline Asian Development Bank & $10 \%-12 \%$ & Conventional administrative rate \\
\hline \multicolumn{3}{|c|}{ Developed countries } \\
\hline Germany & $3 \%$ & Based on the federal refinancing rate \\
\hline Canada & $10 \%$ & Social opportunity cost of capital \\
\hline Spain & $\begin{array}{l}6 \% \text { for transport } \\
4 \% \text { for water }\end{array}$ & Social rate of time preference \\
\hline $\begin{array}{l}\text { United States, Office of } \\
\text { Management and Budget }\end{array}$ & $7 \%$ & Social opportunity cost of capital \\
\hline $\begin{array}{l}\text { United States, Congressional Budget } \\
\text { Office and General Accounting Office }\end{array}$ & Treasury debt market rate & Social rate of time preference \\
\hline $\begin{array}{l}\text { United States, Environmental } \\
\text { Protection Agency }\end{array}$ & $\begin{array}{l}\text { Intergenerational discount rate: } 2 \%-3 \% \text {, } \\
\text { subject to sensitivity analysis }\end{array}$ & Social rate of time preference \\
\hline
\end{tabular}


Table 1 (concluded)

\begin{tabular}{|c|c|c|}
\hline Institution or country & Rate & Conceptual or theoretical basis \\
\hline France & $4 \%$ & Social rate of time preference \\
\hline Norway & $3.5 \%$ & Real government borrowing rate \\
\hline United Kingdom & $\begin{array}{l}3.5 \% \\
\text { Lower differentiated rates for } \\
\text { projects of over } 30 \text { years }\end{array}$ & Social rate of time preference \\
\hline \multicolumn{3}{|c|}{ Developing countries } \\
\hline China & $\begin{array}{l}8 \% \text { for short- and medium-term projects; } \\
\text { less than } 8 \% \text { for long-term projects }\end{array}$ & $\begin{array}{l}\text { Weighted average of the social rate of time } \\
\text { preference and the rate based on the social } \\
\text { opportunity cost of capital (Harberger method) }\end{array}$ \\
\hline India & $12 \%$ & Social opportunity cost of capital \\
\hline Pakistan & $12 \%$ & Social opportunity cost of capital \\
\hline \multicolumn{3}{|c|}{ Latin American countries } \\
\hline Chile & $6 \%$ & $\begin{array}{l}\text { Weighted average of the social rate of time } \\
\text { preference and the rate based on the social } \\
\text { opportunity cost of capital (Harberger method) }\end{array}$ \\
\hline Colombia & $12 \%$ & $\begin{array}{l}\text { Equivalent to the minimum return } \\
\text { expected by the investor }\end{array}$ \\
\hline Mexico & $\begin{array}{l}10 \% \\
\text { before } 2014: 12 \%\end{array}$ & $\begin{array}{l}\text { Weighted average of the social rate of time } \\
\text { preference and the rate based on the social } \\
\text { opportunity cost of capital (Harberger method) }\end{array}$ \\
\hline Peru & $\begin{array}{l}9 \% \\
\text { before 2012: } 10 \%\end{array}$ & $\begin{array}{l}\text { Weighted average of the social rate of time } \\
\text { preference and the rate based on the social } \\
\text { opportunity cost of capital (Harberger method) }\end{array}$ \\
\hline
\end{tabular}

Source: J. Campos, T. Serebrisky and A. Suárez-Alemán, Tasa de descuento social y evaluación de proyectos: algunas reflexiones prácticas para América Latina y el Caribe, Inter-American Development Bank (IDB), 2016; J. Zhuang and others, "Theory and practice in the choice of social discount rate for cost-benefit analysis: a survey", ERD Working Paper, No. 94, Asian Development Bank (ADB), 2007; E. Aldunate and R. Martner, "Fiscal policy and social protection", CEPAL Review, No. 90 (LC/G.2323P), Santiago, Economic Commission for Latin America and the Caribbean (ECLAC), 2006; Chile: National Investment System of the Ministry of Social Development; Colombia: National Public Investment System of the National Planning Department; Mexico: Public Investment System of the Ministry of Finance and Public Credit; Peru: National Public Investment System of the Directorate General of Public Investment of the Ministry of Economy and Finance.

The economic and financial literature groups the various mechanisms for estimating the SDR into three broad approaches. The first sets out from the consumer's point of view, with the discount being derived from social preferences for present consumption (impatience), expectations of future consumption and pure time preferences (Dasgupta and Pearce, 1972). This method is known as the social rate of time preference. Using this approach, Zhuang and others (2007) set out to estimate the SDR in two ways: (i) by considering returns on government bonds or some other low-risk instrument (markets with periods longer than 20 years have yet to be developed) and (ii) by estimating the various components of the Ramsey (1928) equation:

$$
r_{t}=\delta+\eta\left(C_{t}\right) \frac{d C_{t}}{C_{t}}
$$

In most of the cases observed, estimates converge on this second alternative, setting out from macroeconomic aproximations of the parameters of equation (1). The SDR $r_{t}$ is arrived at by aggregating two elements: (i) pure time preferences $(\delta)$ and (ii) the product of two factors: the intertemporal elasticity of consumption $\left(\eta\left(C_{t}\right)\right)$ and the real annual rate of per capita consumption growth $\left(\frac{d C_{t}}{C_{t}}\right)$. Using this method, Zhuang and others (2007), for example, estimated the SDR for several Asian countries, including Indonesia, Japan and Singapore, for which they obtained rates of $6.1 \%, 4.5 \%$ and $7.3 \%$, respectively. The European Commission (2008) also calculates social discount levels for a number of its member countries. In the cases of Denmark, France, Germany and Italy, the results yield rates of $3.1 \%, 3.5 \%, 3.4 \%$ and $3.3 \%$, respectively. A general observation from international experience is that the results are lower than the rate applied in a number of developing countries, such as Chile, Colombia, India and Peru (see table 1). In these countries, and even in Ecuador, there is still a need for a more 
comprehensive assessment of the SDR that takes account of changes in welfare conditions resulting from historical public investment processes.

The second approach to SDR estimation takes the perspective of the producer (firm) as its starting point. The basic principle of this methodology is that the government directly invests funds that could otherwise be used by the private sector, and companies therefore lose the opportunity to employ these resources in economically profitable initiatives. In this context, the SDR must give the minimum project return sufficient to cover the profits lost to the private sector (Edwards, 2016). This approach is known as the social opportunity cost of capital.

In an undistorted economic environment, the SDR estimated from both approaches (the social rate of time preference and the social opportunity cost of capital) should converge on the real interest rate in the economy. However, assuming a market without failures is unrealistic; subsidies, taxes and externalities not absorbed by the price system, among other things, all distort economic relationships. In this context, the discount rates resulting from one and the other strategy will differ (Campos, Serebrisky and Suárez-Alemán, 2015). From the point of view of capital, if it is assumed that trade is open, that capital can move freely around the world and that exchange rates are flexible, the SDR will be given by the interest rate on external borrowing, duly adjusted for the expected price of the foreign currency when servicing the debt (Fontaine, 2000). One of the limitations of this method is that the international market has not carried out transactions covering very long periods (more than 30 years), which means that rates approximating to the prices of capital over distant evaluation horizons cannot be generated. In practice, planning institutions usually assume a constant discount rate, i.e. they take the rates generated in existing (short-term) markets and assume equivalence for rates over long and very long periods. This is a technical limitation in the evaluation of public projects that survive intergenerationally even though they are only evaluated at market rates for shorter terms, e.g. up to 20 years.

The United States Office of Management and Budget (OMB) and the Treasury Board of Canada Secretariat, applying the social opportunity cost of capital methodology, have estimated and use rates of $7 \%$ and $10 \%$, respectively, in the cost-benefit assessment of their public investment projects. In some cases, applying this approach yields rates higher than those actually applied; Pakistan and the Philippines, for example, estimate SDRs of $12 \%$ and $15 \%$, respectively. In most of the cases studied (see Zhuang and others, 2007, for examples), however, the estimated SDRs are lower than the administrative rate.

A third approach to estimating the SDR is that of Harberger (1972). This approach considers the discounting preferences of both consumers and firms; financing comes from these sources (displacement of consumption and sacrifice of private profits). In this context, the SDR is a weighted average of the marginal rate of time preference $(\delta)$ and the marginal rate of return on equity $(R)$, including the respective adjustments for risk and taxes. In summary, the idea put forward describes a rate as follows: $S D R=\alpha R+(1-\alpha) \delta$, where $\alpha$ is the proportion of resources obtained by displacing private investment funds and $(1-\alpha)$ is the proportion of resources generated by displacing present consumption. Multilateral agencies such as the World Bank and the Inter-American Development Bank (IDB) recommend this method in their manuals. Countries such as China, Mexico and Peru have applied this methodology and obtained rates of $8 \%, 10 \%$ and $9 \%$, respectively.

In recent years, the development of knowledge, the application of experimental and behavioural economics to identify individual preferences and the use of intergenerational equity analysis to gauge the effects of public investment have challenged traditional methods of estimating the SDR. The limitations of these methods matter because the allocation of social resources is subject to economic evaluation, in which the SDR is a crucial parameter. There are several alternative estimation methods that deal with these limitations, including the use of time-varying (usually declining) rate mechanisms (Weitzman, 2001) or alternative discounting models, e.g. the hyperbolic model (Mazur, 1987). In this paper, we implement these alternatives and recommend the use of a set of decreasing discount rates, with some adjustments. 


\section{Methodology}

This section details the mathematical derivation of the SDR from the gamma estimation model. In addition, the data collection techniques are described and the present value bias adjustment process proposed for the estimates in a short-term context is outlined.

\section{Gamma discounting}

On the basis of the above arguments supporting the use of a decreasing discount rate, this paper adapts the gamma discounting methodology proposed by Weitzman (2001) and the extension proposed by Edwards (2016) to estimate a set of discount rates for Ecuador. One of the advantages of this methodology is that it recognizes the difficulty and uncertainty involved in determining an SDR, and it consequently proposes a simple mechanism which integrates the perceptions of a group of experts into a single discount factor. In addition, the model demonstrates that aggregating the views of a group of individuals leads to convergence on a structure of decreasing discount rates, even when at the individual level each subject identifies with an exponential discounting mechanism, the kind typically employed in practice.

The model proceeds from two basic arguments. The first is that there is no consensus, at least with regard to the short run, on the value of the SDR that should be applied to projects with benefits and costs in the long run (e.g. more than 20 years and 50 years). In practice, economists use various methods to determine an approximate level, looking at the marginal productivity of capital or the elasticity of consumption, for example, or estimating individual preferences over time. Each method prioritizes a specific aspect of public investment analysis; intergenerational equity, technological change, distortions in the economy, effects on the environment and the presence of externalities are all among the issues of interest (Correa, 2008a). The second argument asserts that to integrate the whole range of opinions and types of respondents captured in a probability distribution, discount functions rather than reported rates should be averaged. To understand this assumption, we take the example given by Edwards (2016). Suppose that two sensible and perfectly informed individuals consider that the SDR should be 10\% and $7 \%$, respectively. If equal weight is given to the two opinions, then the present value of one dollar in 15 years will be given by $0.5(1 / 1.10)^{15}+0.5(1 / 1.07)^{15}=0.3001$; however, this value will be lower if the reported discount rates are weighted directly instead $(1 / 1.085)^{15}=0.2941$.

A further assumption of the model is that it represents the individual discount structure via the standard model. ${ }^{2}$ In other words it is assumed that, as individuals, people assign weightings over time by way of an exponential arrangement $D=e^{-r t}$, where the discount rate reported is given by $\frac{D^{\prime}}{D}$ and is equal to the $r$ parameter for all time delays $t .{ }^{3}$ In practical terms, although a great deal of experimental information suggests that individual discount rates decrease over time (see, for example, Mazur, 1987; Benhabib, Bisin and Schotter, 2010; Castillo and Zhangallimbay, 2018), the most common applications take an exponential function as a model of analysis; it is thus easy to assume that the opinions obtained proceed from this benchmark model. Lastly, the model incorporates what the author defines as "irreducible uncertainty", assuming that the suggested rates (opinions) follow a gamma probability distribution. In this case, the decreasing function of the discount rate is generated by individual uncertainty about the value that the rate may have in distant periods of time and not necessarily by a pattern of individual preferences differing from the traditional one, like the hyperbolic model.

To put it simply, imagine an executive in charge of analysing a socially important project for an international development institution. Uncertain about whether to accept the project, the executive

\footnotetext{
2 Weitzman (2001) concludes that, even if all respondents state that the discount rate is constant, the effective discount rate declines sharply over time.

3 represents the first derivative of the exponential discount function $D$.
} 
decides that the best way to assess its economic viability is by seeking the opinion and collaboration of a group of experts, who are charged with proposing an ideal discounting mechanism to transform monetary units into equivalent terms. The general problem is represented as follows:

$$
\int_{0}^{\infty} A(t) Z(t) d t
$$

Where $Z(t)$ is the net benefit and $A(t)$ the discount factor integrated into each period $t$. If flows $Z(t)$ are given, then the factor $A(t)$ must be the result of considering the $j$ opinions provided by the experts $A_{j t}$. The executive responsible for making the decision knows that he or she must consider the opinion of all the experts before determining an SDR; however, there is no one right way of doing so. This is where assumptions come in. The exponential structure $A_{j t}=e^{-x_{t} t}$ for every $j=1,2, \ldots, n$ makes it possible to model the process whereby the opinions and the respective discount rates $x_{j}$ are generated. Furthermore, the gamma distribution assumption determines the probability that $x_{j}$ (opinions) will take a particular value $x$ by means of the following function:

$$
f(x)=\frac{\beta^{\alpha}}{\Gamma(\alpha)} x^{\alpha-1} e^{-\beta x}
$$

Where the integrated discount factor $A(t)$ is the weighted average of the discount factor or function of each member of the group:

$$
A(t)=\frac{\beta^{\alpha}}{\Gamma(\alpha)} \int_{0}^{\infty} x^{\alpha-1} e^{-(\beta+t) x} d x
$$

$\alpha$ and $\beta$ are parameters of the gamma function that are estimated from the data. The implicit discount rate $R_{t}$ is given by:

$$
R(t)=-\frac{A^{\prime}(t)}{A(t)}
$$

Where $A^{\prime}(t)$ is the first derivative of the integrated discount factor $A(t)$. Resolving (4) and (5) yields the SDR:

$$
R(t)=-\left(\frac{\beta}{\beta+t}\right)^{\alpha}
$$

From equation (6), it can easily be deduced that a decreasing discount rate structure is the result of aggregating or integrating the various opinions via the gamma probability distribution. This characterization of discounting is compatible with several behavioural theories that suggest the existence of inconsistent preferences at the aggregate level (decreasing rates), even when preferences at the individual level are consistent (constant rates). One of the advantages of applying the gamma probability distribution is that its parameters $\alpha$ and $\beta$ can be expressed in terms of the sample mean $(\mu)$ and the standard deviation $\sigma$ of the data:

$$
\begin{aligned}
& \alpha=\frac{\mu^{2}}{\sigma^{2}} \\
& \beta=\frac{\mu}{\sigma^{2}}
\end{aligned}
$$


Substituting (7) and (8) into equation (6) gives the effective SDR in terms of the sample mean and variance:

$$
R(t) \equiv \frac{\mu}{1+\frac{\sigma^{2}}{\mu} t}
$$

Lastly, equation (9) indicates an inverse relationship between the SDR and the uncertainty measure $\sigma$ of the sample. Moreover, the function treats time as a continuous variable. To deal with the SDR from a discrete point of view, Weitzman (2001) determines the average for five defined time intervals: the immediate future (year 1-year 5), average 4\%; the near future (year 6-year 25), average 3\%; the medium future (year 26-year 75), average 2\%; the distant future (year 76-year 300), average 1\%; and the far distant future (year 300 onward), average $0 \%$. In the present case of application to Ecuador, bearing in mind some operational criteria for the evaluation of public investment projects, the rates are evaluated for the time intervals indicated in table 2.

Table 2

Evaluation horizon

\begin{tabular}{cl}
\hline Interval (years) & Evaluation horizon \\
\hline $0-5$ & Immediate future \\
\hline $6-20$ & Medium future \\
\hline $21-50$ & Distant future \\
\hline $51-100$ & Far distant future \\
\hline
\end{tabular}

Source: Prepared by the authors.

Note: Time intervals established in the analysis.

Estimating the SDR by the gamma estimation method involves a discounting approach different to the earlier ones (Harberger, 1972); the result is a discount parameter that decreases depending on the evaluation horizon of the investment project. Again, its application emphasizes the analysis of the opportunity cost of resources over time, so that the resulting SDR is unaffected by changes in other economic prices (account or efficiency prices) and does not affect them in its turn.

Previous approaches to estimating the constant SDR have taken as a benchmark, among other alternatives, estimates of the average productivity of capital based on marginally accepted projects whose economic evaluation was carried out by adjusting market prices to efficiency prices in order to calculate the internal rate of economic return. This practice has several limitations. First, profit flows for projects that are approved tend to be overestimated, so that the average productivity of capital may only constitute a benchmark for the upper bound or maximum discount rate. Second, there are major information constraints; not only is it difficult to identify a representative sample of investment projects evaluated at efficiency prices, but it is also typical for there to be significant delays in updating efficiency prices, and State planning offices or development banks seldom instigate review processes. On top of this, regional integration dynamics have reduced the distortions that necessitate adjustments to market price conversion factors, examples being tariff reduction policies, the removal of subsidies, tax cuts, etc.

The gamma method applied in this study is insulated from these issues in that the benchmark information is derived from an independent decision instrument applied to decision-makers. The perception captured by this instrument is based on the project evaluation experience of those participating in the study, so that a priori it can be stated that their decision should encapsulate all the elements of analysis presented, without regard to the need to update factor efficiency prices for the economic evaluation of investment projects. 


\section{Data and adaptation}

To apply the proposed method, a survey was conducted among a group of experts, analysts and decision-makers working on issues related to investment analysis and the evaluation of public and private investment projects. The group included four categories of people: teaching staff from the faculties of economics and administration of various universities (academics), postgraduate students in the areas of economics and business (master's students), financial sector managers and analysts connected to the country's association of private banks (financiers) and managers or business people connected to the chambers of industry, production and commerce (business people). ${ }^{4}$ In the data collection process, 950 survey questionnaires were sent out via email. The surveys were designed and distributed using the SurveyMonkey digital tool. Arrangements were also made to confirm receipt of the emails and present the study to participants, both directly and through the associations of which they are members. The response rate was $28 \%$. A total of 269 completed surveys were obtained, distributed among the four reference groups of the study. ${ }^{5}$ Table 3 presents the composition of the sample.

Table 3

Composition of the sample of persons answering the survey designed for the study

\begin{tabular}{lcc}
\hline Category & Frequency & Percentage \\
\hline Academics & 167 & 62.08 \\
\hline Master's students & 82 & 30.48 \\
\hline Financiers & 5 & 1.86 \\
\hline Businesspeople & 11 & 4.08 \\
\hline Total & 269 & 100 \\
\hline
\end{tabular}

Source: Prepared by the authors.

Note: The survey was applied digitally using the SurveyMonkey tool.

Weitzman (2001) directly asked respondents about the SDR parameter for discounting the benefits and costs of climate change mitigation projects. ${ }^{6}$ The question he put in his study was: Taking all relevant considerations into account, what real interest rate do you think should be used to discount over time the (expected) benefits and (expected) costs of projects being proposed to mitigate the possible effects of global climate change?

However, there are several drawbacks to this procedure. Some respondents state that they do not have sufficient knowledge in this area to give an opinion; others speak of the need to have differentiated rates for developed and developing countries; lastly, others clearly fail to understand the question. Problems of understanding can be encountered even in groups of experienced people, which can lead to biases in their answers and estimates. However, differences in opinions and value judgements regarding discounting mechanisms have more fundamental reasons related to intergenerational welfare and the allocation of public resources, among other issues (Weitzman, 2001). To minimize confusion, Edwards (2016) proposes a different survey methodology, using three hypothetical questions which are easy to understand and whose collection structure is adaptive, i.e. dependent on previous responses. In this way, instead of a single parameter, a range of discount rates is obtained from each respondent (see annex A1). ${ }^{7}$

4 The authors would like to thank the Association of Private Banks of Ecuador (ASOBANCA) and the Chamber of Industries and Production (CIP) for their collaboration with this survey.

5 We would like to highlight the quality of the responses received and the consistency between the answers and the control questions.

6 The sample for this study totalled around 2,100 observations, including experts and economists from all over the world.

7 Respondents choose between two possible investment projects, one generating profits valued at US\$1.5 million over 15 years and one generating US\$ 2.5 million over 30 years. 
The survey used for the present study consists of three questions presenting a choice between investment projects with long-term benefits. To capture potential design bias in the magnitude of the parameter, three versions of the questionnaire (E1, E2 and E3) were designed (see, for example, Coller and Williams, 1999; Harrison and others, 2005). Each version differs in the amounts generated by the investment projects: low amounts, medium amounts and high amounts (see annex A2). ${ }^{8}$ In addition, each version allows four discount ranges to be specified: as the amounts increase, the discount ranges also differ, so that a total of 12 discount ranges are available (see table 4). For reasons of simplicity and efficiency, the midpoint of each range is taken as an approximate indication of the SDR for each respondent. ${ }^{9}$ The overall range of the 12 options is from $0.98 \%$ to $14.13 \%$. The range includes the current administrative rate of $12 \%$ as a validation mechanism.

Table 4

Discount ranges

(Percentages)

\begin{tabular}{lccc}
\hline Survey & Lower bound & Upper bound & $\begin{array}{c}\text { Approximate social } \\
\text { discount rate (SDR) }\end{array}$ \\
\hline E1 & 0 & 1.96 & 0.98 \\
\hline E1 & 1.96 & 3.41 & 2.69 \\
\hline E1 & 3.41 & 6.54 & 4.98 \\
\hline E1 & 6.54 & - & 6.54 \\
\hline E2 & 0 & 4.62 & 2.31 \\
\hline E2 & 4.62 & 7.32 & 5.97 \\
\hline E2 & 7.32 & 10.73 & 9.03 \\
\hline E2 & 10.73 & - & 10.73 \\
\hline E3 & 0 & 3.41 & 1.70 \\
\hline E3 & 3.41 & 10.73 & 7.07 \\
\hline E3 & 10.73 & 14.13 & 12.43 \\
\hline E3 & 14.13 & - & 14.13 \\
\hline
\end{tabular}

Source: Prepared by the authors.

Note: The surveys are distributed independently.

Lastly, some individual characteristics of participants are also collected to assess their possible relationship with discount levels, including age, gender, work experience, number of children, risk aversion and others (see table 5).

Table 5

Sample characteristics

\begin{tabular}{lcccrr}
\hline & N & Mean/proportion & Standard deviation & Minimum & Maximum \\
\hline Female & 199 & 0.32 & 0.47 & 0 & 1 \\
\hline Education level & 200 & 3.12 & 0.55 & 2 & 4 \\
\hline Age & 199 & 38.28 & 8.90 & 23 & 63 \\
\hline Has children & 200 & 0.61 & 0.49 & 0 & 1 \\
\hline Work experience (years) & 200 & 14.94 & 8.59 & 2 & 43 \\
\hline Risk aversion & 207 & 6.70 & 1.99 & 1 & 10 \\
\hline Risk (DOSPERT) & 207 & 4.98 & 1.43 & 1.33 & 9 \\
\hline
\end{tabular}

Source: Prepared by the authors.

Note: Some respondents did not answer the survey in full, so there are discrepancies in the observations. The education level categories are: 1 = secondary, 2 = university, 3 = postgraduate, 4 = doctorate. Risk aversion is determined by a self-reported measure of willingness to take risks, on a scale of 1 to 10. The DOSPERT score is the average of the self-reported measures of risk in six areas: driving a vehicle, finance, sports, health, work and trust in others.

8 While this process does not completely correct the framing problem, it allows for greater variation in the discount rates approximated by the survey, capturing a wider range of discount preferences.

9 Edwards (2016) considers it necessary to estimate the SDR when a discount range is obtained; however, this approach does not represent a significant change in the sample mean and variance that are needed in gamma estimation, as compared to the application of a rate approximated by the midpoint of the range. 


\section{Adjusting for short-term preferences}

In the gamma discounting methodology, the data collection mechanism is generally expressed in a context of long-term preferences. While an individual with time-consistent preferences should theoretically maintain the same intertemporal discount structure in the short and long terms, present value bias, i.e. the temptation to obtain immediate returns when they are imminent, is an anomaly that produces distortions between the two approaches. Because the Edwards (2016) methodology does not properly capture preferences in short-term periods, we adjust our results by including the following question in the survey: What is the minimum amount you would be willing to receive today (in dollars) rather than 200 dollars in three months' time?

An effective discount rate ${ }^{10}$ determined in a three-month lag period is derived from the reported value. A value for each respondent's annual effective rate is obtained by applying rate equivalence. Using the same opinion integration mechanism, a general decreasing discount rate function can be estimated on the basis of lag $t$ (years). The question is whether this exercise reflects behaviour similar to that observed for the integrated discount function in the original long-term mechanism. Although the original mechanism proposes a context in which there is a choice of investment projects with returns in periods that are far off in time, the mechanism is not immune to individual preferences. Therefore, if there are substantial differences in the rates determined by each of the functions over the different time intervals set, a better approximation to the SDR must be an average of the resulting rates.

\section{Results}

First, the results obtained using the original survey mechanism are analysed from a long-term perspective. Figure 1 presents the frequency histogram of the approximate discount rates collected and obtained using the three questions in the three versions of the survey applied to experts, academics, master's students, financiers and businesspeople. The gamma discounting methodology was used to integrate preferences, and a decreasing function of the SDR was estimated.

Equation (9) suggests that the SDR is equal to the weighted average of the $\mu$ data when $t=0$; in the present case, this rate is $7.17 \%$. In the estimation mechanism, $t=0$ corresponds to periods shorter than the minimum period included in the survey, which is 15 years. The instantaneous rate in our results is higher than the value of 3.96\% obtained by Weitzman (2001) and that of 4.92\% obtained by Edwards (2016) in the case of Chile, but lower than the value of $10.76 \%$ found by Correa (2008b) for Colombia. The standard deviation $\sigma$ of our data is 3.0024, which is lower than that found for Colombia (Correa, 2008b) and close to that of Weitzman (2001). Substituting the parameters $\mu$ and $\sigma$, the effective discount rate for each period $t$, according to the method used by Weitzman (2001), is given by:

$$
R(t)=\frac{7.1722}{1+\frac{(3.0024)^{2}}{7.1722}}
$$

\footnotetext{
${ }^{10}$ When the exponential model is applied, the amount (present value) reported by participants is equal to, where $r$ is the individual discount rate.
} 
Figure 1

Histogram of the social discount rate (SDR)

(Percentages)

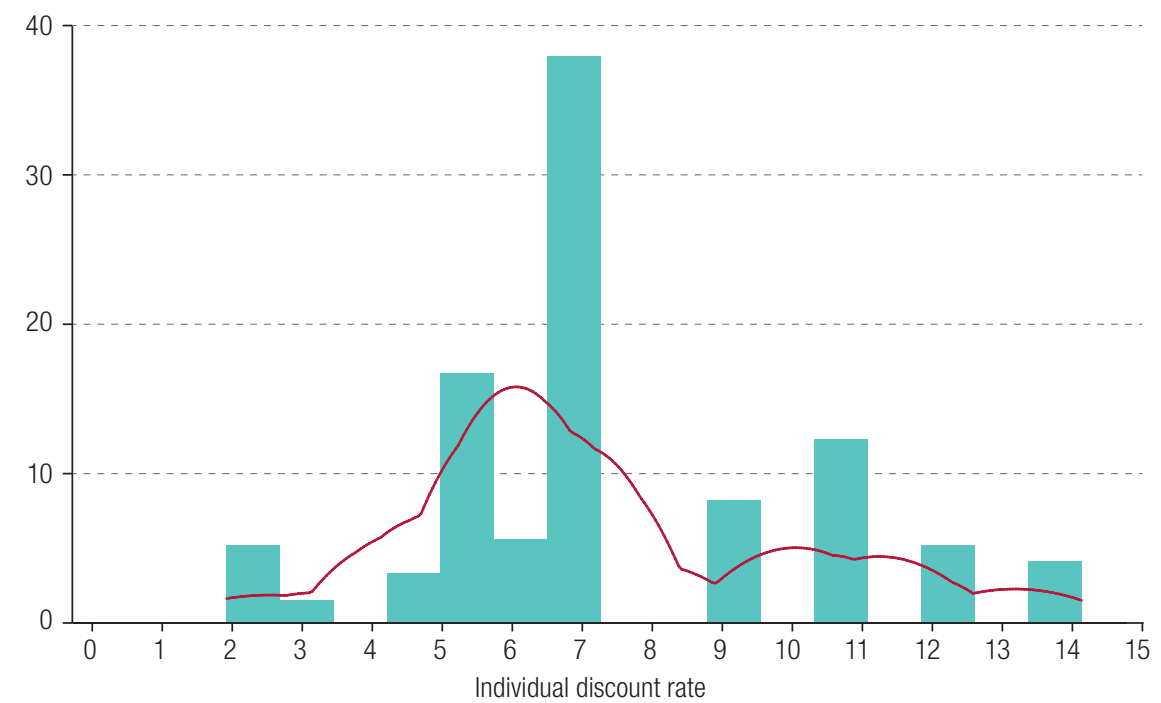

Source: Prepared by the authors, on the basis of the social discount rate obtained from a three-question survey.

An important point is that in short-term periods, e.g. periods of less than 15 years, the proposed methodology has difficulty in reflecting social preferences. ${ }^{11}$ For practical reasons, however, the estimates in this study assume consistent behaviour from the earliest years. Thus, to evaluate public investment projects in Ecuador, the economic flow generated by the investment in year 5 should be discounted at a rate of $6.87 \%$, while the flows generated in years 15 and 30 should be discounted at rates of $6.03 \%$ and $5.21 \%$, respectively. Note that only one rate is estimated for each year's lag. However, equation (12) can be used to determine a rate that is constant and equivalent $(\bar{R})$ to the decreasing process of the discount rate.

$$
\bar{R}=\frac{1}{\int_{0}^{\infty} A(t) d t}
$$

Substituting equation (3) into (9) gives:

$$
\bar{R}=\frac{(\mu-\sigma)(\mu+\sigma)}{\mu}
$$

The constant equivalent rate for our estimates is 5.91\% per annum, which is considerably lower than the administrative rate applied by several countries and some multilateral organizations. In relation to other similar estimates in the region, the equivalent rate $(\bar{R})$ is lower than that obtained in Colombia (8.0\%) and higher than that estimated by Weitzman (2001) (1.43\%).

Figure 2A shows the dynamics of the integrated SDR. A fairly moderate decrease can be observed, from a rate of about $7 \%$ for the first year to one of about $3 \%$ for the hundredth year.

\footnotetext{
${ }^{11}$ Edwards (2016) recognizes that the rates that can be inferred by his methodology are only consistent if is a year subsequent to the starting year established in the survey, which in our case is year 15.
} 
Figure 2

Estimated long-term social discount rate (SDR)

(Percentages)

A. Continuously decreasing SDR

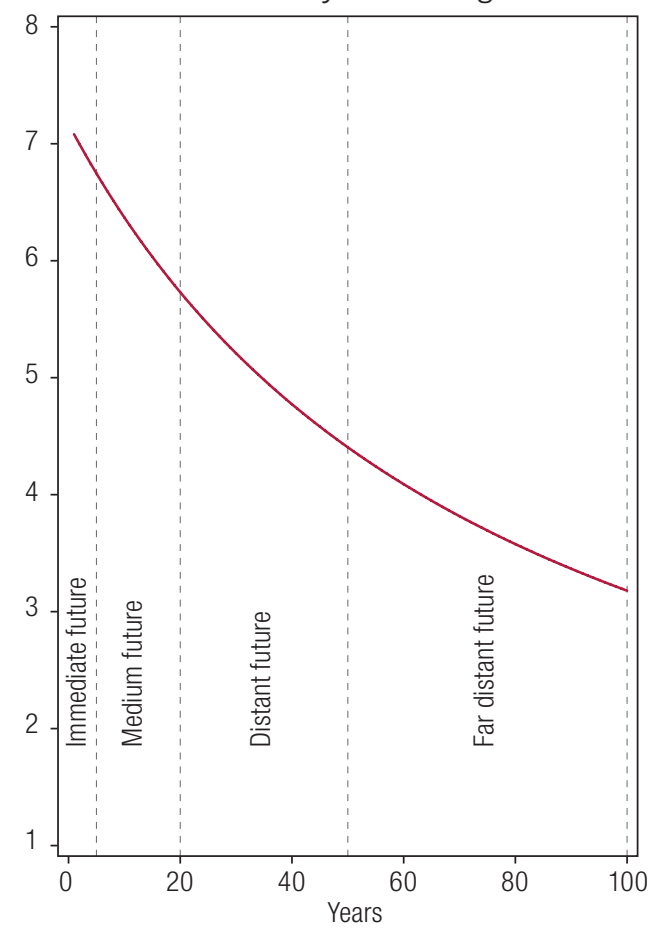

B. SDR decreasing by intervals

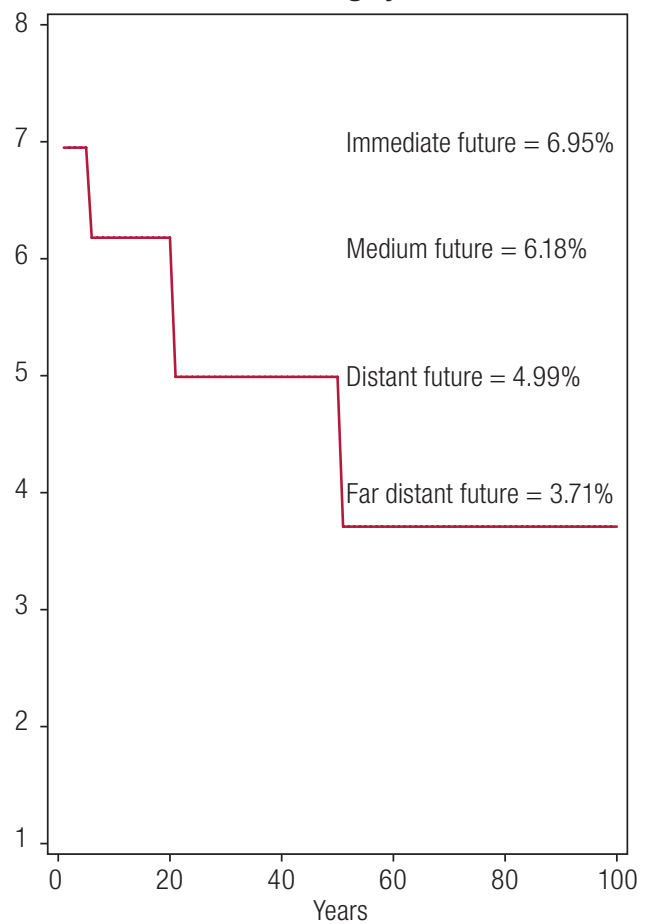

Source: Prepared by the authors, on the basis of the preference estimation mechanism (survey).

To implement a decreasing discount approach, thus capturing in the assessment criteria the large body of information that supports this discounting dynamic, the time intervals identified earlier can be used. In each segment, the SDR values are grouped by the average of the function in the time interval corresponding to the evaluation horizon. Figure 2 shows the dynamics of the SDR for Ecuador. Preliminary results suggest a discount of around $7.0 \%$ for the flows in the first 5 years, $6.0 \%$ for the next 15 years, $5.0 \%$ for the next 30 years and $3.7 \%$ for the next 50 years. A rate of $1.0 \%$ can be applied when assessing projects with longer-lasting effects (a horizon of more than 100 years) (see figure 2B). While in practice these assessment horizons are not commonly used, particularly in the region, in the United States, for example, the Environmental Protection Agency (EPA) uses horizons of more than 100 years to analyse its many research programmes, including the Air, Climate, and Energy programme, the Chemical Safety for Sustainability programme and the Safe and Sustainable Water Resources programme.

The basic assumption of the estimates is that, by its structure, the survey compels subjects to consider options for benefits to future generations, so that benefit preferences for their own generation (short term) are underestimated. To correct for potential inconsistencies in the estimations of rates for the short term, i.e. the immediate future and the medium future, the question about individual preferences over time is analysed for a period of three months and with a future value of US\$200. The information collected by this question does not have a predetermined range in the survey design and, unlike Edwards (2016), we avoid adding the hypothetical context of public investment projects, instead directly obtaining individual preferences over time.

The results yield significantly higher rates than those determined by the original mechanism in Weitzman (2001). The range is from $1 \%$ to in excess of $200 \%$. This result potentially derives from two sources: (i) the magnitude of the hypothetical reward in the question, which artificially makes the present 
more attractive, or (ii) pure present value bias, irrespective of the proposed amount. Even so, it is still possible to assume that individual preferences regarding the discount rate follow a gamma probability distribution (see figure 3). Consequently, the expert opinions are aggregated, the aggregate discount function is determined and the function for the SDR is estimated for the lags of $t$. The results show discount rates of $14 \%, 2 \%, 1 \%$ and $0 \%$ for the immediate future, the medium future, the distant future and the far distant future, respectively (see figure 4).

Figure 3

Annual discount rate (short term)

(Percentages)

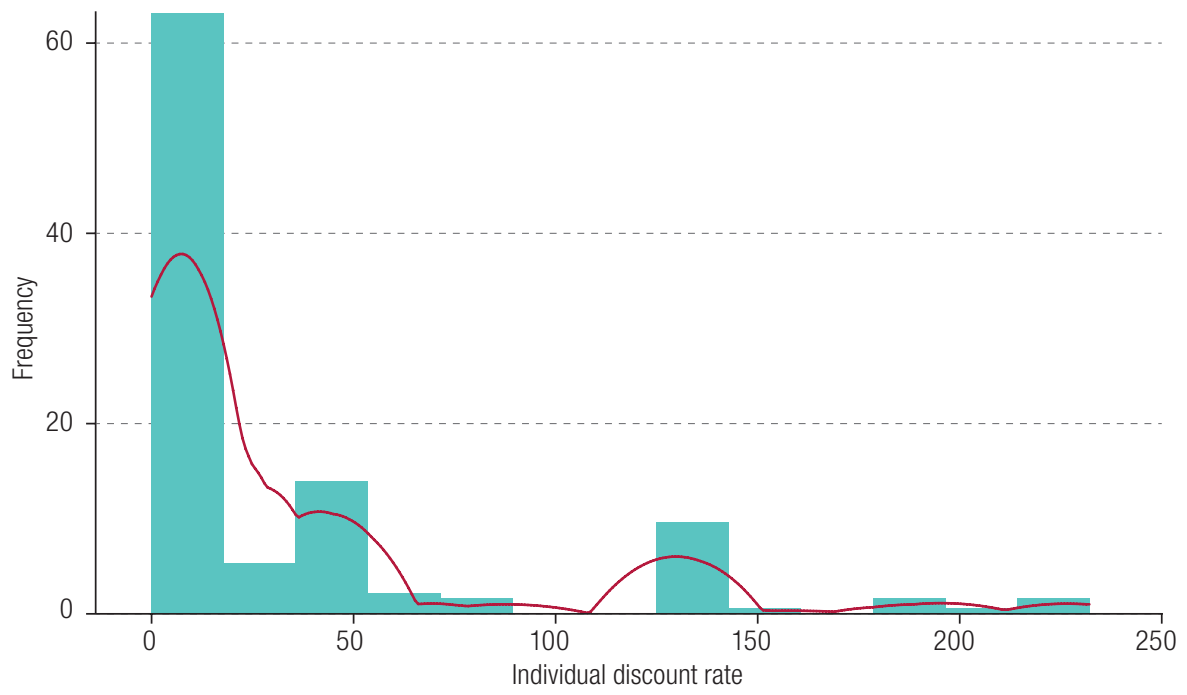

Source: Prepared by the authors, on the basis of the preference estimation mechanism (survey).

Figure 4A shows the dynamics of the annual rates estimated with the short-term estimation mechanism. In contrast to what is observed in figure 2, the process shows a more rapid decline than in the initial (long-run) context, possibly owing to the increase in the standard deviation $(\sigma)$ of the data in this mechanism. Considering both the magnitude and variance effects of the response, what would be expected for the estimated rates in the short-run context is a steeper decline curve, but with higher rates than in the long-run context. However, our results show a considerable increase in the early years (for example, the estimated function suggests an SDR of over $120 \%$ for discounting the flow generated in the first year), while for year 100 the suggested SDR is lower than that of the long-term context, at about $0 \%$.

Much as in other studies (see Herrnstein, 1961; Ainslie and Herrnstein, 1981; Loewenstein and Prelec, 1992; Coller and Williams, 1999; Manzini and Mariotti, 2007; Benhabib, Bisin and Schotter, 2010; Castillo and Zhangallimbay, 2018), the above results reveal the inconsistencies of individual preferences with respect to time and the context of analysis (see figure 5). The preference elicitation mechanisms, like the SDR estimation alternatives, are not universally consistent and are sensitive to the method of exposure or framing employed in the data collection questionnaire. In the face of this instrumental dilemma, and considering that the alternatives proposed are more cost-effective than largerscale elicitation options, what is proposed is harmonization of the implicit biases in the two contexts, given that they reflect respondents' opinions and social preferences. It is also interesting to note that the estimated rates for the immediate future ( $1-5$ years) in both the short- and long-term scenarios are in the range of $7 \%-14 \%$, which the standard administrative rates usually employed fall into. In other words, our estimates suggest that these rates are good evaluation parameters for short-term projects 
(less than 5 years); for longer evaluation horizons, however, these rates over-devalue the future net flows generated by a project, in a process where preferences for high returns in short periods of time predominate over the search for a balance of benefits taking account of the effect on future generations.

\section{Figure 4}

Estimated short-term social discount rate (SDR)

(Percentages)

A. Continuously decreasing SDR

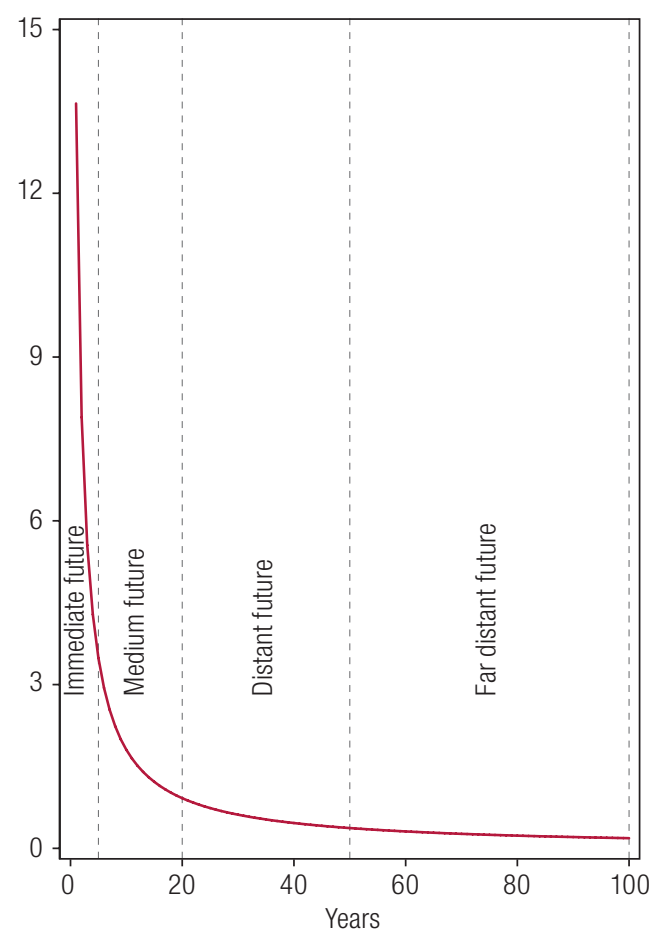

B. SDR decreasing by intervals

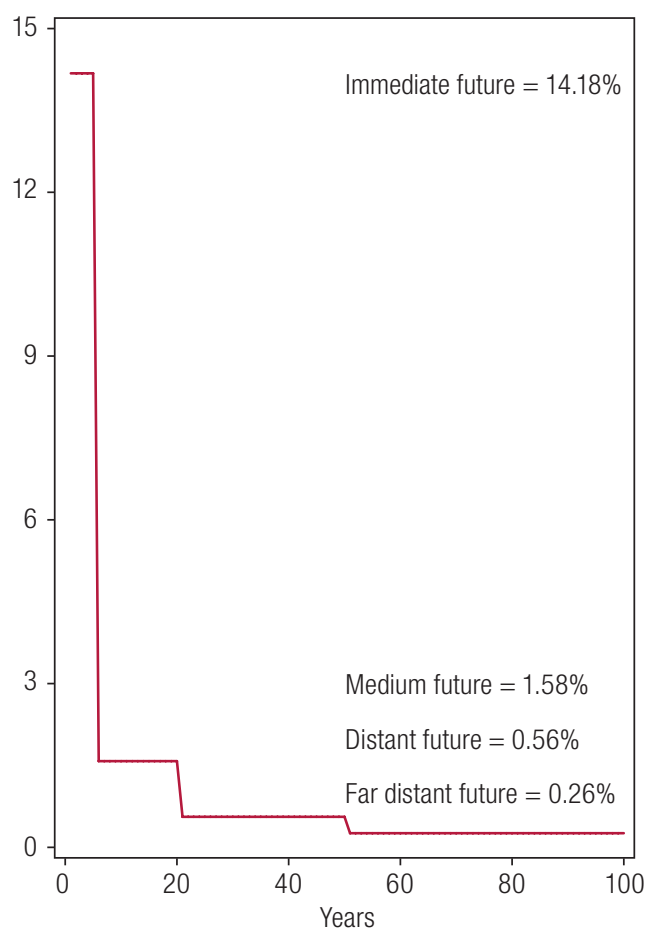

Source: Prepared by the authors, on the basis of the preference estimation mechanism (survey).

To harmonize the two approaches and adjust the estimates for the short- and long-term elicitation contexts, the average of the functions of the two estimates is evaluated. The solid line in figure 5 shows this dynamic. The high rates observed in the short-term context make it possible to adjust the component not considered by the Edwards methodology, which is precisely what prevents appropriate discount rates from being established for the early years of a project's life. In this case, correction is achieved by obtaining information from the agents themselves, emphasizing the need to determine more precisely the value of short-term returns, especially those that are potentially received in their own generation.

When these adjustment elements are considered in our estimates, the results suggest the application of a rate of about $11 \%$ for discounting economic flows generated in the immediate future (the first 5 years), about $4 \%$ for flows generated in the next 15 years, about $3 \%$ for the next 30 years and about $2 \%$ for the last 50 years, within a reference horizon of 100 years. Once again, if the assessment period extends beyond 100 years, a rate of $1 \%$ is recommended. 
Figure 5

Social discount rate (SDR) adjusted for the short and long terms and for the average of these (Percentages)

A. Continuously decreasing SDR

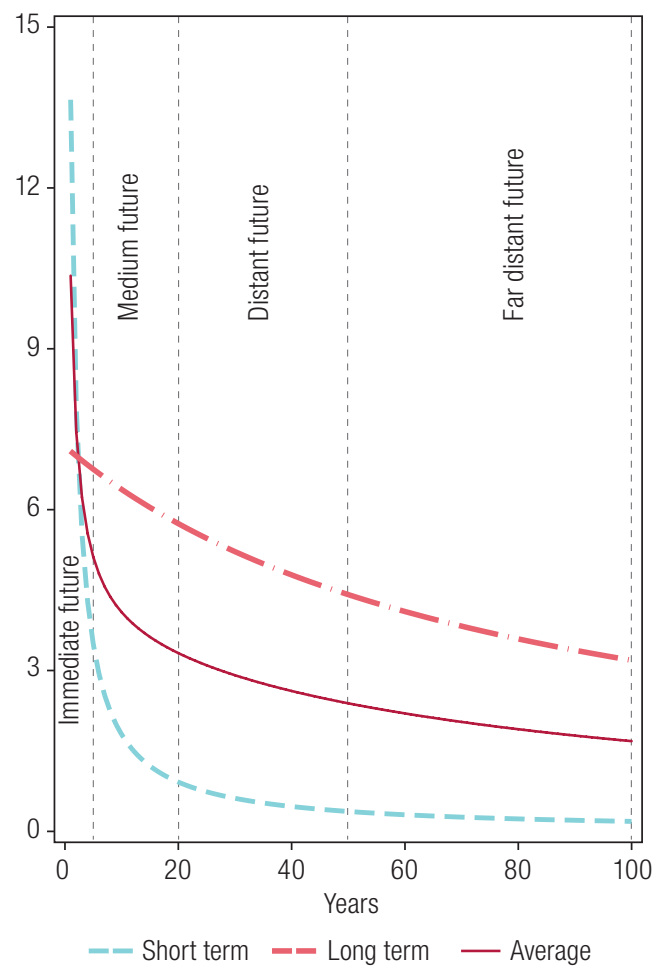

B. SDR decreasing by intervals

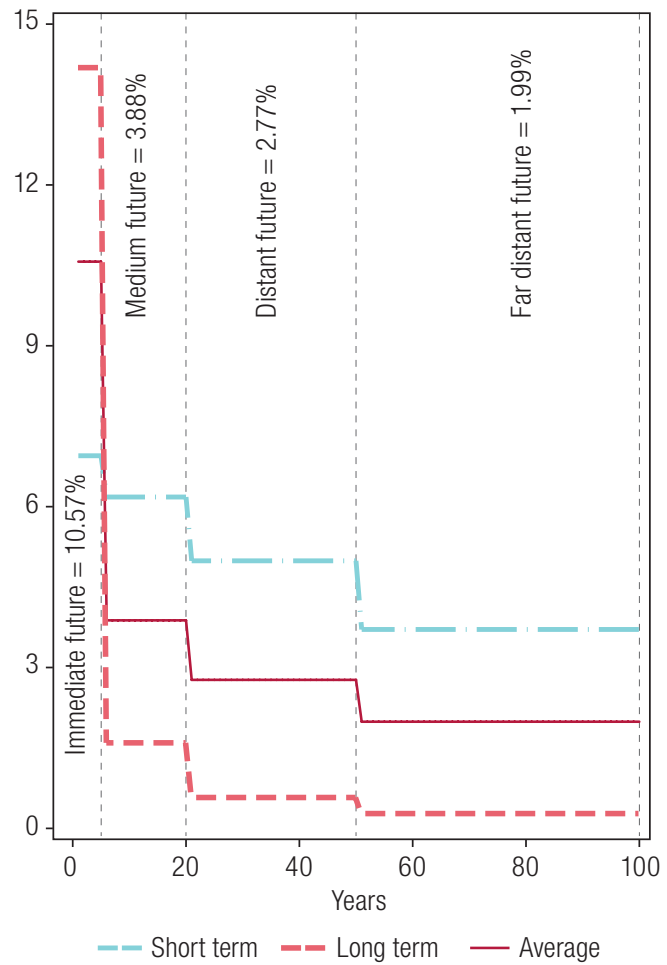

Source: Prepared by the authors, on the basis of the preference estimation mechanism (survey).

\section{Determinants of long-term preferences}

As an additional element of analysis providing important information about the type of answers given by the experts consulted, we analyse whether there is a relationship between individual characteristics and the time preferences reported, specifically with regard to the long term. The information collection questionnaire gathers a battery of data on participants' individual characteristics, including gender, age, work experience, level of education and level of risk aversion. In addition, the structure of the three-question survey used to obtain the SDR specifies four preference intervals arranged in ascending order and assigned on the basis of each subject's responses. The two supplementary versions of the survey present an increase in the magnitude of the benefits of public investment projects; however, they offer other discount intervals with different rates that are higher on average. Interval regression analysis was used to assess the relationship between the individual discount rate and the characteristics of the survey participants.

Table 6 presents the results. Two dichotomous variables capture the fixed effect of the additional versions of the survey (survey 2 and survey 3). Because the rates identified are higher on average in the two supplementary versions, a positive and significant relationship was found for one of these variables. That is, there is a framing effect in the way individual discount rates are obtained, something that should be taken into account in the design of questionnaires. In addition, a positive relationship between age and SDRs is observed, albeit a weak one (statistically significant only at 10\%), which is apparent only when the estimation includes controls for individual preferences (risk aversion). In terms of behaviour, this result suggests that discounting behaviour changes with age, an observation documented in other 
research; however, the observed relationship is the reverse of what has been found in other studies: the greater the age, the higher the discount rate. While this result may reflect respondents' levels of impatience or self-control, its low significance means that we have opted not to draw any further conclusions from it. Lastly, we find empirical evidence supporting the relationship between time and risk preferences (significant at 10\%), insofar as more risk-averse individuals tend to report a preference for higher discount rates (i.e. a greater preference for the present).

Table 6

Determinants of time preferences

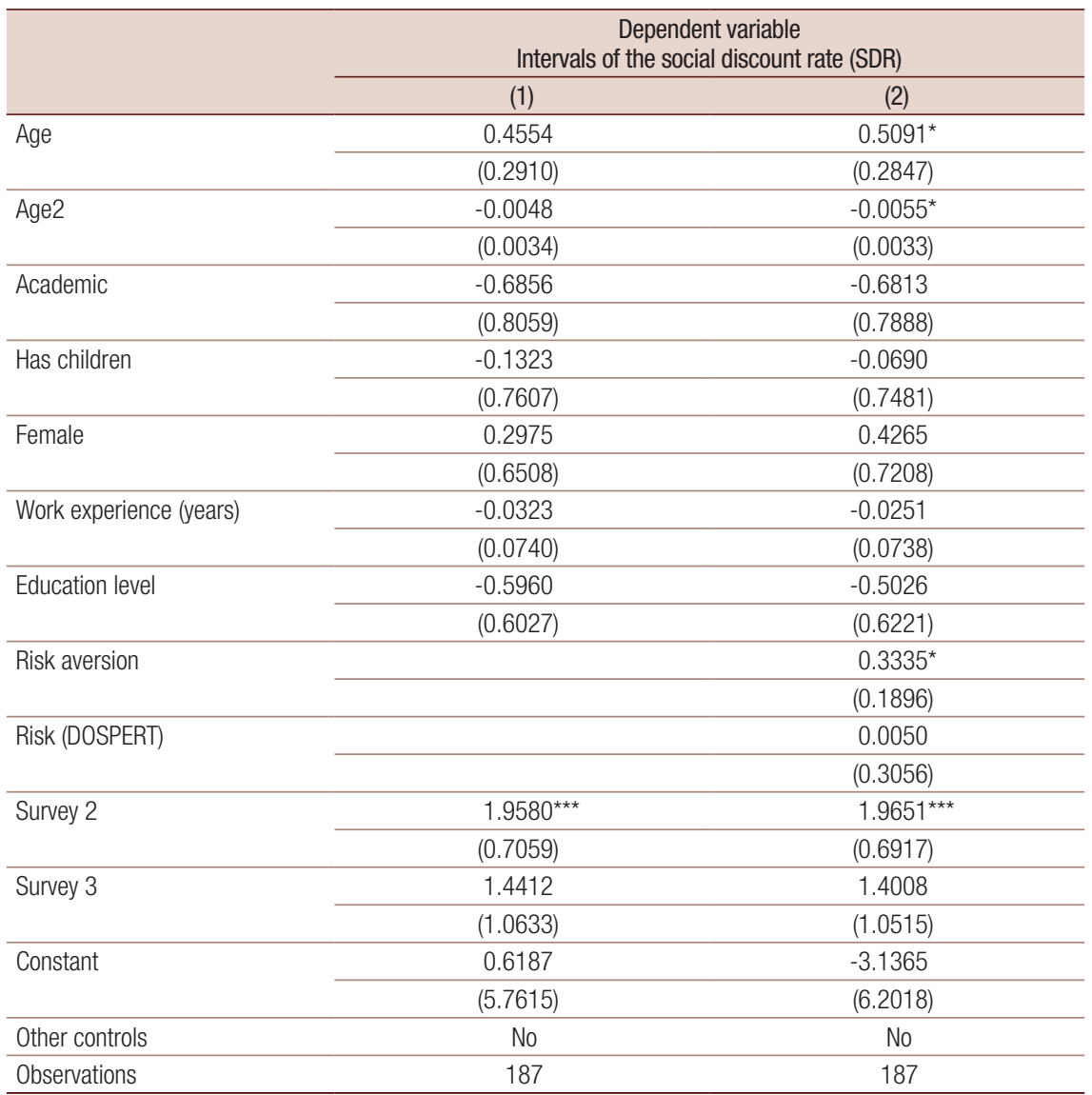

Source: Prepared by the authors.

Note: Participants for whom all information is available are considered (187). Risk aversion is determined by a self-reported measure of willingness to take risks, on a scale of 1 to 10 . The DOSPERT score is the average of self-reported risk aversion in six areas (driving a car, finance, sports, health, work and trust in others).

Robust standard errors are shown in brackets.

* Significant at $10 \%$; ${ }^{* *}$ significant at $5 \%$; ${ }^{* \star}$ significant at $1 \%$.

\section{Conclusions}

The SDR is a key parameter for economic and financial project evaluation. Cost-benefit analysis decisions, both in investment appraisal and in broader analyses such as those related to climate change, depend crucially on its level. However, despite its importance, there is considerable uncertainty as to the appropriate level for each country or context of analysis, and in most cases a simple approach has been chosen: to use a common administrative rate. In Ecuador, as in other countries of the region, an unvarying rate of $12 \%$ is used; however, this rate is very far from incorporating the changing dynamics of social preferences over time. 
This paper identifies the need to continuously update the parameters required for the appraisal of public investments. It presents a cost-effective alternative for estimating the SDR that captures the wealth of empirical information on behaviour in respect of inconsistencies in time discounting and discount rates that decrease over time (hyperbolic discounting), while adjusting the estimates for the difference in context between short- and long-term decisions.

The results, adjusted for the time context by averaging the short- and long-term functions, yield a different level of discounting for four time horizons: the immediate future (approximately $11 \%$ ), the medium future (approximately 4\%), the distant future (approximately 3\%) and the far distant future (approximately $2 \%$ ). In this context, the administrative rates commonly applied are justified on the basis of the evaluation of profit flows obtained in the immediate future (5 years), which generates significant distortions in the economic valuation of investment projects.

\section{Bibliography}

Ainslie, G. and R. Herrnstein (1981), "Preference reversal and delayed reinforcement", Animal Learning Behavior, vol. 9.

Aldunate, E. and R. Martner (2006), "Fiscal policy and social protection", CEPAL Review, No. 90 (LC/G.2323-P), Santiago, Economic Commission for Latin America and the Caribbean (ECLAC).

Benhabib, J., A. Bisin and A. Schotter (2010), "Present-bias, quasi-hyperbolic discounting, and fixed costs", Games and Economic Behavior, vol. 69.

Campos, J., T. Serebrisky and A. Suárez-Alemán (2016), Tasa de descuento social y evaluación de proyectos: algunas reflexiones prácticas para América Latina y el Caribe, Inter-American Development Bank (IDB). (2015), "Porque el tiempo pasa: evolución teórica y práctica en la determinación de la tasa social de descuento", Nota técnica del BID, No. IDB-TN-861, September.

Castillo, J. and D. Zhangallimbay (2018), "Las preferencias Individuales y sus determinantes: un análisis de las preferencias sobre el tiempo y el riesgo", Economic Sciences master's thesis, Guayaquil, ESPOL-Polytechnic University.

Coller, M. and M. Williams (1999), "Eliciting individual discount rates", Experimental Economics, vol. 2.

Correa, F. (2008), "Tasa de descuento ambiental Gamma: una aplicación para Colombia", Lecturas de Economía, vol. 69.

(2008), "Un análisis teórico de las propuestas alternativas para la determinación de la tasa social de descuento de largo plazo", Semestre Económico, vol. 11.

Dasgupta, A. and D. Pearce (1972), Cost-Benefit Analysis: Theory and Practice, Palgrave Macmillan.

Delacámara, G. (2008), "Guía para decisores: análisis económico de externalidades ambientales", Project Documents (LCN.200), Santiago, Economic Commission for Latin America and the Caribbean (ECLAC).

Edwards, G. (2016), "Estimación de la tasa social de descuento a largo plazo en el marco de los sistemas nacionales de inversión: aplicación al caso chileno", El Trimestre Económico, vol. 329.

European Commission (2008), Guide to Cost-Benefit Analysis of Investment Projects [online] https://ec.europa. eu/regional_policy/sources/docgener/guides/cost/guide2008_en.pdf.

Fontaine, E. (2000), Evaluación Social de Proyectos, Alfaomega Editores.

Frederick, S., G. Loewenstein and E. D. O'Donoghue (2002), "Time discounting: a critical review", Journal of Economic Literature, vol. 40.

Harberger, A. (1972), "On measuring the social opportunity cost of public funds", Project Evaluation-Collected Papers, chap. 4, Chicago, The University of Chicago Press.

Harrison, G. and others (2005), "Eliciting risk and time preferences using field experiments: some methodological issues", Research in Experimental Economics, vol. 10.

Herrnstein, R. (1961), "Relative and absolute strengths of response as a function of frequency of reinforcement", Journal of Experimental and Analysis Behavior, vol. 4.

Lowe, A. J. (2008), Intergenerational wealth transfers and social discounting: Supplementary Green Book guidance, HM Treasury.

Loewenstein, G. and D. Prelec (1992), "Anomalies in intertemporal choice: evidence and interpretation", Quarterly Journal of Economics, vol. 107. 
Manzini, P. and M. Mariotti (2007), "Choice Over Time”, IZA Discussion Paper, No. 2993 [online] papers.ssrn. com/sol3/papers.cfm?abstract_id=1012547.

Mazur, J. (1987), "An adjusting procedure for studying delayed reinforcement", Quantitative Analyses of Behavior: The Effect of Delay and of Intervening Events on Reinforcement Value, vol. 5, M.L. Commons (eds.), Erlbaum, Hillsdale.

Ramsey, F. (1928), "A mathematical theory of saving", Economic Journal, vol. 38.

Sampedro, J. L. (2009), "El problema de las áreas económicamente deprimidas y su planteamiento actual en la Gran Bretaña", Economía humanista: algo más que cifras, J. L. Sampedro, Madrid, Debate.

— (1999), "Una visión del subdesarrollo hace 30 años", Revista de Economía Mundial, vol. 1. (1972), Conciencia de subdesarrollo, Barcelona, Salvat.

Sampedro, J. L. and R. Martínez Cortiña (1975), Estructura económica: teoría básica y estructura mundial, Barcelona, Ariel.

Thaler, R. (1981), "Some empirical evidence on dynamic inconsistency", Economic Letters, vol. 8.

Weitzman, M. (2001), "Gamma discounting", American Economic Review, vol. 91.

Zhuang, J. and others (2007), "Theory and practice in the choice of social discount rate for cost-benefit analysis: a survey", ERD Working Paper, No. 94, Asian Development Bank (ADB). 


\section{Annex A1}

\section{Three-question survey}

(i) If you had to decide today between two projects, a government project generating returns that can be valued at US\$1.5 million over 15 years and a government project generating returns that can be valued at US $\$ 2.5$ million over 30 years, which would you choose?

- US\$1.5 million over 15 years

- US\$2.5 million over 30 years

(ii) You chose the project generating US\$1.5 million over 15 years over the project generating returns of US $\$ 2.5$ million over 30 years.

If now the returns of the second option rose to US\$ 4.0 million with the same time horizon (30 years), which option would you choose?

- US\$1.5 million over 15 years

- US\$ 4.0 million over 30 years

(iii) You chose the project generating US\$ 2.5 million over 30 years over the project generating returns of US $\$ 1.5$ million over 15 years.

If now the returns of the 30-year project fell to US\$2.0 million, which option would you choose?

- US\$1.5 million over 15 years

- US\$2.0 million over 30 years

\section{Estimating the social discount rate (SDR) interval}

For example, if someone answered that they chose the project generating returns valued at US\$ 2.5 million over 30 years over the project generating US\$ 1.5 million over 15 years, we get:

$$
\begin{aligned}
& 1.5 e^{-15 r}<2.5 e^{-30 r} \\
& \ln \left(1.5 e^{-15 r}\right)<\ln \left(2.5 e^{-30 r}\right) \\
& \ln (1.5)-15 r<\ln (2.5 e)-30 r \\
& r<3,41 \%
\end{aligned}
$$

If this individual answered in the next question that they chose the project generating US\$ 2.0 million over 30 years over the one generating US\$1.5 million over 15 years, we get:

$$
\begin{gathered}
1.5 e^{-15 r}<2 e^{-30 r} \\
r<1.96 \%
\end{gathered}
$$

Consequently, this individual's answer, $r<1.96 \%$, is in the first proposed SDR range. 


\section{Annex A2}

\section{Survey versions}

Table A2.1

Amounts in the surveys

\begin{tabular}{lcc}
\hline Version & Time & $\begin{array}{c}\text { Amount } \\
\text { (dollars) }\end{array}$ \\
\hline Survey 1 (low amounts) & 15 years & 1.5 million \\
\cline { 2 - 3 } & 30 years & 2.5 million \\
\cline { 2 - 3 } & 30 years & 2.0 million \\
\cline { 2 - 3 } Survey 2 (medium amounts) & 30 years & 4.0 million \\
\cline { 2 - 3 } & 15 years & 5.0 million \\
\cline { 2 - 3 } & 30 years & 15.0 million \\
\hline Survey 3 (high amounts) & 30 years & 10.0 million \\
\cline { 2 - 3 } & 30 years & 25.0 million \\
\cline { 2 - 3 } & 15 years & 15.0 million \\
\cline { 2 - 3 } & 30 years & 5.0 million \\
\hline
\end{tabular}

Source: Prepared by the authors.

Note: The surveys were applied randomly. 